\title{
Increased alveolar/capillary membrane resistance to gas transfer in patients with chronic heart failure
}

\author{
S Puri, B L Baker, C M Oakley, J M B Hughes, J G F Cleland
}

\begin{abstract}
Objective-To investigate pulmonary diffusive resistance to gas exchange in patients with heart failure and healthy volunteers, assessing the relative contributions of the alveolar/capillary membrane and pulmonary capillary blood.

Setting-Hospital outpatient department and pulmonary function laboratory.

Patients-38 patients (mean age 60) receiving treatment with loop diuretics and angiotensin converting enzyme inhibitors for stable symptomatic heart failure of $>6$ months duration (New York Heart Association (NYHA) classes II and III). Results were compared with those of 17 healthy volunteers (mean age 52). Methods-The alveolar/capillary membrane diffusive resistance and the pulmonary capillary blood volume available for physiological gas exchange were determined by the Roughton and Forster method, which measures the single breath pulmonary diffusing capacity for carbon monoxide at varying alveolar oxygen concentrations.
\end{abstract}

Results-Total pulmonary diffusive resistance was higher in patients than controls. Alveolar/capillary membrane resistance formed the main component of this increase, accounting for a mean (SD) of $63 \%(20 \%)$ and $86 \%(8 \%)$ of total pulmonary diffusive resistance in patients in NYHA II and III classes respectively, compared with $53 \%(10 \%)$ in controls. The pulmonary capillary blood volume was not significantly different between controls and patients in NYHA class II (66 (18) $\mathrm{ml} v 61$ (18) $\mathrm{ml}$ ), but was increased in those in NYHA class III (95(46) $\mathrm{ml}, \mathrm{P}<0.05)$.

Conclusion-This study confirmed impairment of pulmonary diffusion at rest in patients with chronic heart failure and identified impaired alveolar/capillary membrane function as the main factor responsible.

(Br Heart F 1994;72:140-144)

A reduction in resting pulmonary diffusing capacity to carbon monoxide (TLCO) has been previously reported in patients with chronic heart failure,,$^{1-3}$ but the precise aetiology of this reduction remains unclear. It has been assumed that a decrease in TLCO was not of functional significance as arterial desaturation is not prominent during exercise in patients with heart failure, ${ }^{4}$ and during exercise the relatively reduced cardiac output and prolonged pulmonary capillary transit time would allow increased time for gas exchange in the lung.

More recently, TLCo has been proposed as being an independent predictor of peak exercise oxygen uptake in patients with heart failure. $^{5}$ Also, increasing inspired oxygen concentration during exercise has been shown to improve arterial oxygen saturation, reduce minute ventilation, and improve breathlessness. ${ }^{6}$ These data suggest that impairment of pulmonary gas exchange may be a limiting factor for exercise performance.

In patients with mitral stenosis, who also have high left atrial pressures, detailed studies of pulmonary function have been performed, ${ }^{78}$ including measurement of alveolar/capillary membrane diffusing capacity $\left(D_{M}\right)$ and pulmonary capillary volume (VC)..$^{9}$ In this group, reduction in DLCO and $D_{M}$ have been shown to be associated with New York Heart Association (NYHA) functional class ${ }^{9}$ and histological lung damage. ${ }^{10}$ No such measurements of $D_{M}$ and VC have been made in patients with symptomatic heart failure. The aim of our study was to investigate pulmonary diffusive resistance ( 1 TLCO) to gas exchange in patients with heart failure compared with normal controls, with particular reference to the relative contributions of the alveolar/capillary membrane and pulmonary capillary blood.

\section{Patients and methods}

PATIENTS

The study was approved by the local ethics committee, and each patient gave informed consent. Patients with a history of respiratory disease or who were current smokers were excluded. Thirty six men and two women with stable symptomatic heart failure of $>6$ months duration, mean age 60 (range 39-75) were studied. The mean (SD) left ventricular ejection fraction as determined by gated radionuclide ventriculography was $33 \%$ $(10 \%)$. The aetiology of heart failure was ischaemic heart disease in 32 and dilated cardiomyopathy in six patients. Twenty eight patients were in NYHA class II and 10 in NYHA class III. All were receiving loop diuretic treatment, a mean (SD) frusemide equivalent dose of 45 (21) $\mathrm{mg}$ (assuming $1 \mathrm{mg}$ of bumetanide is equivalent to $40 \mathrm{mg}$ of frusemide), and angiotensin converting enzyme (ACE) inhibitors. None had needed a 
change in treatment in the eight weeks before the study. Three of the patients studied (all in NYHA class II) were being treated with amiodarone, and no patients were receiving other drugs that may have had an effect on the measurement of TLCO. Healthy volunteers (one woman and $16 \mathrm{men}$ ), mean age 52 (range 38-67), without a history of cardiorespiratory disease and with a normal physical examination were also studied.

\section{PROCEDURE}

Routine spirometry was performed to determine the forced expiratory volume in one second $\left(F E V_{1}\right)$ and slow vital capacity (VC). The TLCO was measured in duplicate with a standard modified Krogh single breath technique (PK Morgan). ${ }^{112}$ The test gas consisted of $0.28 \%$ carbon monoxide (CO) and $14 \%$ helium $(\mathrm{He})$ in air. Briefly, the patient was connected with a mouth piece and nose clip to a double bag in box system with a three way valve. After four or five tidal breaths of room air, a maximal expiration was made to residual volume and the valve was automatically switched so that the subject inhaled maximally from the bag containing the test gas mixture, a vital capacity. This was followed by a predetermined (10 s) period of breath holding at full inspiration. Leakage of gas from the patient was prevented by the closure of a shutter. A further automatic switch of the three way valve allowed the subject to exhale naturally. The first $750 \mathrm{ml}$ of expired gas was discarded with collection of the next $500 \mathrm{ml}$ in a second bag for subsequent gas analysis. This manoeuvre was then repeated, again in duplicate, with a test gas with a higher oxygen $\left(\mathrm{O}_{2}\right)$ concentration $(0.3 \% \mathrm{CO}, 10 \% \mathrm{He}, 89.7 \%$ $\mathrm{O}_{2}$ ). All results were corrected for the subject's haemoglobin concentration. The alveolar partial pressure of $\mathrm{O}_{2}\left(\mathrm{P}_{\mathrm{A}} \mathrm{O}_{2}\right)$ was recorded for all TLCO measurements and was estimated from the fractional expired $\mathrm{O}_{2}$ concentration of the same expired gas sample used for the measurement of TLCO (Servomex $\mathrm{O}_{2}$ analyser $570 \mathrm{~A})$. It was assumed that the partial pressure of $\mathrm{H}_{2} \mathrm{O}$ in the alveolus was $47 \mathrm{~mm} \mathrm{Hg}$. DM and the volume of blood available for physiological gas exchange were determined with the classic Roughton and Forster method. ${ }^{112}$ This method partitions pulmonary resistance capacity (1/TLCO) into its two component resistances: the diffusive resistance of the alveolar capillary membrane $\left(1 / D_{M}\right)$ and the reactive resistance due to pulmonary capillary blood $(1 / \theta \mathrm{Vc}$, where $\theta=$ the rate of reaction of $\mathrm{CO}$ with haemoglobin).

Table 1 Anthropometric details and results of routine lung function tests

\begin{tabular}{lccc}
\hline & $\begin{array}{l}\text { Controls } \\
(n=17)\end{array}$ & $\begin{array}{l}\text { NYHA } \\
\text { class II } \\
(n=28)\end{array}$ & $\begin{array}{l}\text { NYHA } \\
\text { class III } \\
(n=10)\end{array}$ \\
\hline Height $(\mathrm{m})$ & $1 \cdot 72(0 \cdot 09)$ & $1 \cdot 70(0 \cdot 07)$ & $1 \cdot 73(0 \cdot 09)$ \\
Weight $(\mathrm{kg})$ & $70(11)$ & $79(12)$ & $77(16)$ \\
Body surface area $\left(\mathrm{m}^{2}\right)$ & $1.89(0 \cdot 18)$ & $1.90(0 \cdot 16)$ & $1.90(0 \cdot 23)$ \\
FEV $\mathrm{VC}(\%)$ & $80(9)$ & $75(9)$ & $74(9)$ \\
VC $(1)$ & $4 \cdot 4(0 \cdot 3)$ & $3 \cdot 2(0 \cdot 2)^{\star}$ & $2 \cdot 6(0 \cdot 3)^{\star}$ \\
TLCO $(\mathrm{mmol} / \mathrm{min} / \mathrm{kPa})$ & $9 \cdot 68(2 \cdot 02)$ & $7 \cdot 39(1 \cdot 51)^{\star}$ & $5 \cdot 22(1 \cdot 33)^{\star}$ \\
\hline
\end{tabular}

$\star \mathrm{P}<0.001 v$ controls. TLCo pulmonary diffusing capacity for carbon monoxide; $\mathrm{FEV}_{\mathrm{t}}=$ forced expiratory volume in one second; VC, = vital capacity. Results are mean (SD).

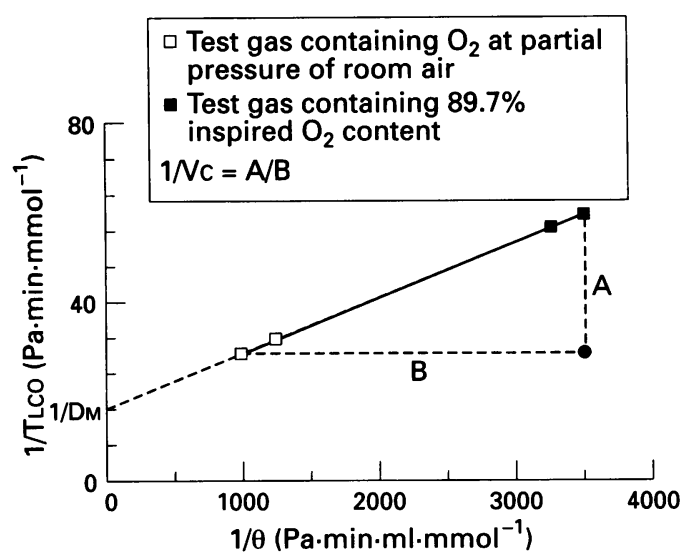

Figure 1 Classic Roughton and Forster method of determining alveolar capillary membrane diffusive resistance $\left(1 / D_{N}\right)$ and pulmonary capillary blood volume (VC). TLCO, pulmonary diffusing capacity for carbon monoxide (CO); $\theta$, the rate of reaction of $C O$ with haemoglobin.

The Roughton and Forster equation ${ }^{11}$ $1 /$ TLCO $=1 / \mathrm{D}_{\mathrm{M}}+1 / \theta$ VC links these resistances together. $\theta$ is inversely proportional to $\mathrm{P}_{\mathrm{A}} \mathrm{O}_{2}$ as there is direct competition for haemoglobin binding sites between $\mathrm{CO}$ and $\mathrm{O}_{2}$. The following equation assumes that the red cell membrane has a negligible resistance to gas exchange, ${ }^{12}$ and was used to find $1 / \theta: 1 / \theta=$ $14.6 / \mathrm{Hb} \times\left(\left(0.001 \times \mathrm{P}_{\mathrm{A}} \mathrm{O}_{2}\right)+0.0134\right)$ where $\mathrm{Hb}=$ the subject's haemoglobin $(\mathrm{g} / \mathrm{dl})$ and $\mathrm{P}_{\mathrm{A}} \mathrm{O}_{2}$ is measured in $\mathrm{kPa}$. Therefore if TLCO is measured at different $\mathrm{P}_{\mathrm{A}} \mathrm{O}_{2}$ values, a plot of 1/DLCo against $1 / \theta$ will yield a straight line with a $\mathrm{Y}$ intercept of $1 / \mathrm{D}_{M}$ and a gradient of 1/VC (fig 1).

\section{STUDIES OF REPRODUCIBILITY}

Repeat measurements were made at about the same time of day on two consecutive days in five controls and five patients with heart failure chosen at random.

\section{STATISTICAL ANALYSIS}

All values are expressed as mean(SD). Comparisons of results between patients with severe symptoms (NYHA class III), patients with mild to moderate symptoms (NYHA class II), and normal controls were made using the Scheffe $F$ test (analysis of variance). $A$ value of $P<0.05$ was considered to be significant.

\section{Results}

Table 1 summarises the results of conventional lung function tests and anthropometric details of the subjects studied. The VC was reduced in patients with heart failure compared with normal controls $(P<0.05)$, but there was no significant increase in airflow obstruction as measured by the $\mathrm{FEV}_{1} / \mathrm{VC}$ ratio (table 1), in keeping with previous studies. $^{23}$

Studies of reproducibility showed a high level of agreement between consecutive measurements of $1 / \mathrm{D}_{\mathrm{M}}$, having a correlation coefficient $(r)$ of 0.99 and a coefficient of vari- 


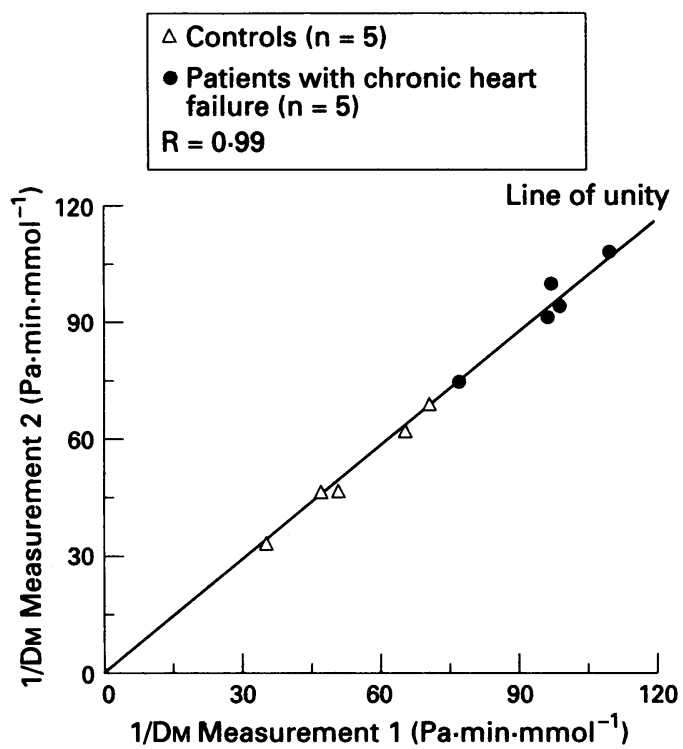

Figure 2 Reproducibility of consecutive measurements of alveolar capillary membrane diffusive resistance $\left(1 / D_{\mu}\right)$.

ation $<5 \%$ (fig 2). Figure 3 plots the individual results of all subjects with respect to $1 /$ TLCO, $1 / \mathrm{D}_{\mathrm{m}}$, and the total pulmonary diffusive resistance (\%) due to the alveolar capillary membrane $\left(100 \times T_{L C O} / \mathrm{D}_{M}\right)$. Table 2 summarises the significance of the differences in these variables. The results of the three patients in NYHA class II receiving treatment with amiodarone did not differ significantly from other patients in this functional class (mean values for $1 / \mathrm{DM}$ and $\mathrm{DLCO} / \mathrm{D}_{\mu}$ were 96 Pa.min.mmol ${ }^{-1}$ and $65 \%$ respectively).

About $50 \%$ of total pulmonary diffusive resistance at rest is due to the alveolar capillary membrane in normal people, ${ }^{13}$ irrespective of age. ${ }^{14}$ The results in our controls concur with this value. The pulmonary diffusive resistance was significantly greater in patients with heart failure than in the controls. The increase found was predominantly due to increased alveolar capillary membrane diffusive resistance and was most prominent in patients in NYHA class III (fig 3). There was no significant correlation between vital capacity and the proportion of total pulmonary diffusive resistance due to the alveolar/capillary membrane resistance $\left(\mathrm{TLCO}_{\mathrm{L}} / \mathrm{D}_{\mathrm{M}}, r=0.24\right)$. The pulmonary capillary blood volume was not significantly different between patients in NYHA class II and controls, similar to the findings in patients with mitral stenosis, ${ }^{9}$ but was increased in those patients in NYHA class III (table 2).

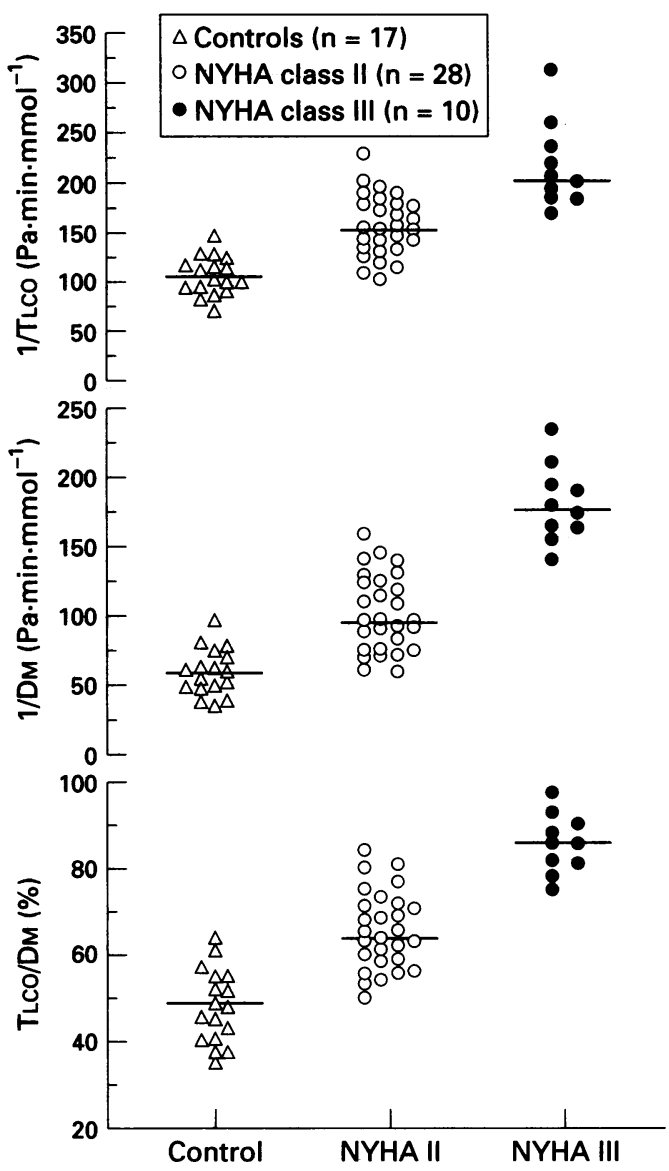

Figure 3 Individual results and median value of each group for total pulmonary diffusive resistance (1/TLCO), alveolar/capillary membrane diffusive resistance $\left(1 / D_{M}\right)$, and the percentage of total pulmonary diffusive resistance due to the alveolar/capillary membrane $\left(100 \times T L C O / D_{M}\right)$

\section{Discussion}

Our results confirm previous reports of a reduced DLCo at rest in patients with chronic heart failure ${ }^{1-3}$ in spite of increased Vc in patients with severe symptoms, and identify increased alveolar capillary membrane resistance to gas exchange as the main factor responsible.

An increase in alveolar/capillary membrane resistance may in theory be secondary to a decrease in the effective surface area of alveolar membrane available for gas exchange (reduced lung volumes, increased ventilation/perfusion mismatch) or an alteration in its physical characteristics (increased thickness or diffusing distance, reduced permeability). Although normal ageing is associated with an increase in total pulmonary diffusive resistance, the alveolar/capillary membrane

Table 2 Pulmonary diffusive resistance and its subdivisions

\begin{tabular}{|c|c|c|c|c|c|c|}
\hline & \multirow{2}{*}{$\begin{array}{l}1 \\
\text { Control } \\
(n=17)\end{array}$} & \multirow{2}{*}{$\begin{array}{l}2 \\
\text { NYHA class } I I \\
(n=28)\end{array}$} & \multirow{2}{*}{$\begin{array}{l}3 \\
\text { NYHA class } I I I \\
(n=10)\end{array}$} & \multicolumn{3}{|l|}{ p Values ${ }^{\star}$} \\
\hline & & & & $1 v 2$ & $1 v 3$ & $2 v 3$ \\
\hline 1/TLCo & $110(20)$ & $140(30)$ & $200(60)$ & $P<0.01$ & $P<0.0001$ & $P<0.0005$ \\
\hline $\begin{array}{l}\text { 1/DM } \\
\left(\mathrm{Pa}_{\mathrm{Pan}} \cdot \mathrm{mmol}^{-1}\right)\end{array}$ & $60(20)$ & $90(30)$ & $170(40)$ & $P<0.001$ & $P<0.0001$ & $P<0.0001$ \\
\hline $\begin{array}{l}\text { TLCO/D } \\
\text { Vc }(\mathrm{ml})\end{array}$ & $\begin{array}{l}53(10) \\
66(18)\end{array}$ & $\begin{array}{l}63(9) \\
61(18)\end{array}$ & $\begin{array}{l}86(8) \\
95(46)\end{array}$ & $\begin{array}{l}P<0.01 \\
\text { NS }\end{array}$ & $\begin{array}{l}P<0.0001 \\
P<0.05\end{array}$ & $\begin{array}{l}P<0.0001 \\
P<0.05\end{array}$ \\
\hline
\end{tabular}

* P Values quoted are for comparisons made with the Scheffe $F$ test for analysis of variance. Thco, total pulmonary diffusive resistance; $1 / \mathrm{DM}$, alveolar capillary membrane diffusive resistance; TLCo/DM, the proportion of total pulmonary diffusive resistance due to the alveolar capillary membrane. VC, volume of pulmonary capillary blood. Results are mean (SD). 
portion of this increase $\left(\mathrm{TLCO}_{\mathrm{L}} / \mathrm{D}_{M}\right)$ remains relatively constant at about $50 \% .^{14}$

A reduction in lung volumes is well documented in patients with heart failure.$^{23}$ If this were to be the main mechanism responsible for the increase in alveolar/capillary membrane diffusive resistance, then a significant correlation between vital capacity and $\mathrm{TLCO} / \mathrm{D}_{\mathrm{M}}$ would be expected. Moreover, a decrease in lung volume would reduce not only DLCO, but also reduce the pulmonary capillary volume of blood available for physiological gas exchange. None of these changes were seen in our patient population, and in contrast, those patients with the greatest increase in alveolar/capillary membrane resistance also had increased pulmonary capillary blood volumes. A recent study of patients undergoing heart transplantation did not show any improvement in TLCO despite a return to normal lung volumes after transplantation, ${ }^{15}$ lending further support to there being an alternative explanation for raised alveolar/capillary membrane resistance to gas exchange in patients with chronic heart failure.

In a similar vein, the presence of increased ventilation/perfusion mismatch would cause a reduction in the effective surface area available for physiological gas exchange, leaving the proportion of total pulmonary diffusive resistance due to the alveolar/capillary membrane $\left(T_{L C O} / \mathrm{D}_{M}\right)$ unchanged, and the effective volume of pulmonary capillary blood reduced. This was not found to be the case in this study, suggesting that increased ventilation/perfusion mismatch is not a main cause of the increased alveolar/capillary membrane resistance seen in our patient population.

A significant determinant of pulmonary capillary volume will be the surface area of the alveolar/capillary interface available for gas exchange. This will be increased by improved ventilation/perfusion matching, and may be one factor responsible for the increase in pulmonary capillary blood volume seen in patients in NYHA class III-for example, increased perfusion of the relatively over ventilated pulmonary upper lobes at rest, secondary to an increase of left atrial pressure.

In patients with mitral stenosis, raised pulmonary diffusive resistance correlates with the degree of histological pulmonary vascular damage. ${ }^{10}$ In animal models, a transient increase in pulmonary artery pressure has been shown to cause disruption of alveolar epithelium and pulmonary endothelium, ${ }^{16}$ which in the short term at least is reversible. ${ }^{17}$ In patients with heart failure, pulmonary capillary pressures may also be increased at rest, ${ }^{18}$ and increase further on exercise. ${ }^{1920}$ This could induce stress damage of the alveolar/ capillary membrane. ${ }^{21}$ Indeed, the earliest changes arising from a rise in pulmonary venous and capillary pressure occur in the alveolar/capillary wall, which becomes oedematous, particularly in the thicker collagen containing parts of the septum. ${ }^{22}$ Hyaline organisation with a mucopolysaccharide ground substance takes place. There is endothelial cell swelling, and proliferation of connective tissue (reticulin and elastin) and type II epithelial cells is seen. ${ }^{22}$ Raised alveolar/ capillary membrane resistance may reflect the nature and magnitude of this injury. Evidence from heart transplant recipients suggests that there may be irreversible pulmonary vascular or parenchymal abnormalities as TLCO decreases despite a restoration of normal haemodynamics ${ }^{1523}$ and lung volumes ${ }^{15}$ after transplantation. This population, however, represents one extreme of the heart failure spectrum. Abnormalities of pulmonary diffusing capacity, and in particular the change in alveolar/capillary membrane resistance that we have found, may be partly or totally reversible in those with less severe disease.

The importance of changes in pulmonary haemodynamics in chronic heart failure is emphasised by the fact that pulmonary hypertension has been shown to predict morbidity and mortality in patients with dilated cardiomyopathy. ${ }^{24}$ The inability to decrease pulmonary as well as systemic vascular resistance has been implicated both in the impairment of exercise performance ${ }^{25}$ and the poor clinical and sometimes hypotensive response to ACE inhibition seen in some patients with heart failure. ${ }^{26}$ These data would support the hypothesis that pulmonary microvascular damage and modulation of pulmonary vascular resistance are in part responsible for the exercise limitation of heart failure. Conventional measures of pulmonary haemodynamics (pulmonary artery pressure, pulmonary capillary wedge pressure, and pulmonary vascular resistance) whether at rest or on exercise, only provide a view of the pulmonary circulation over a brief period. Alveolar/capillary membrane resistance may provide a more useful and sensitive non-invasive marker for the assessment of pulmonary microvascular damage than conventional haemodynamic measures, reflecting the cumulative damage sustained throughout the course of the underlying disease process.

There is increasing evidence that impaired pulmonary function and gas exchange may contribute to the functional limitation of chronic heart failure. ${ }^{56}$ The results of this study support the presence of impaired function of the alveolar-capillary membrane at rest in treated stable chronic heart failure. This dysfunction is greatest in those with the most severe symptoms (NYHA class III), although there is clearly some overlap with controls in patients in NYHA class II. Whether this impairment can be modified or is of significance in the limitation of exercise performance in patients with heart failure remains unknown at present. Further investigation of alveolar/capillary membrane resistance during exercise and with progression of disease is required.

SP is supported by a Research Fellowship from the British Heart Foundation.

1 Siegel JL, Miller A, Brown LK, DeLuca A, Tierstein AJ. Pulmonary diffusing capacity in left ventricular failure. Chest 1990;98:550-3. 
2 Naum CC, Sciurba FC, Rogers RM. Pulmonary function abnormalities in chronic severe cardiomyopathy preceding cardiac transplantation. Am Rev Respir Dis 1992:145. 1334-8.

3 Wright RS, Levine MS, Bellamy PE, Simmons MS, Batra $P$, Stevenson LW, et al. Ventilatory and diffusion abnor$\mathrm{P}$, Stevenson $\mathrm{LW}$, et al. Ventilatory and diffusion abnormalities in potenti.

4 Rubin SA, Brown HV. Ventilation and gas exchange during exercise among patients with severe chronic heart failure. Am Rev Respir Dis 1984;129(suppl):S63-4.

5 Kraemer MD, Kubo SH, Rector TS, Brunsvold N, Bank AJ. Pulmonary and peripheral vascular factors are important determinants of peak exercise oxygen uptake in patients with heart failure. F Am Coll Cardiol 1993; 21:641-8.

6 Moore DP, Weston AR, Hughes JMB, Oakley CM, Cleland JGF. Effects of increased oxygen concentrations on exercise performance in chronic heart failure. Lancet 1992;339:950-3.

7 Rhodes KM, Evemy K, Nariman S, Gibson GJ. Relationship between severity of mitral valve disease and
results of routine lung function. Thorax 1982;37:751-5.

8 Jebavy P, Widimsky J, Stanek V. Distribution of inspired gas and pulmonary diffusing capacity at rest and during graded exercise in patients with mitral stenosis. Respiration 1971;28:216-35.

9 Gazioglu K, Yu PN. Pulmonary blood volume and pulmonary capillary blood volume in vascular heart disease. Circulation 1967;35:701-9.

10 Aber CP, Campbell JA. Significance of changes in the pulmonary diffusing capacity in mitral stenosis. Thorax monary diffusing

11 Roughton FJW, Forster RE. Relative importance of diffusion and chemical reaction rates in determining rate of exchange of gases in human lung, with special reference to true diffusing capacity of pulmonary membrane and volume of blood in the lung capillaries. $\mathcal{F}$ Appl Physiol $1957 ; 11: 2$

12 Cotes JE. Lung function. Oxford: Blackwell Scientific Publications, 1979;246-9.

13 West JB. Ventilation, blood flow, and gas exchange. In: Murray JF, Nadel JA, eds. Textbook of respiratory medicine. Philadelphia: WB Saunders, 1988:68.

14 Chang S-C, Chang H-I, Liu S-Y, Shiao G-M, Perng R-P.
Effects of body position and age on membrane diffusing capacity and pulmonary capillary blood volume. Chest 1992;102:139-42.

15 Ravenscraft SA, Gross CR, Kubo S, Olivari MT, Shumway SJ, Bolman RM, Herz MI. Pulmonary function after successful heart transplantation. Chest tion after succe.

16 Costello ML, Mathieu-Costello O, West JB. Stress failure of alveolar epithelial cells studied by scanning electron Respir Dis 1992;145:1446-55.

17 Elliot AR, Fu Z, Tsukimoto K, Prediletto R, MathieuCostello O, West JB. Short-term reversibility of ultrastructural changes in pulmonary capillaries caused by stress fracture. $\mathcal{f}$ Appl Physiol 1992;73:1150-8.

18 Franciosa JA, Leddy CL, Wilen M, Schwartz DE. Relation between haemodynamic and ventilatory responses in determining exercise capacity in severe congestive heart failure. $A m \mathcal{F}$ Cardiol 1984;53:127-34.

19 Fink LI, Wilson JR, Ferraro N. Exercise ventilation and pulmonary artery wedge pressure in chronic stable congestive heart failure. Am $\mathcal{F}$ Cardiol 1986;57:249-53.

20 Higginbotham MB, Sullivan NJ, Simonton CA, Morris KG, et al. Determinants of variable exercise performance in patients with severe left ventricular dysfunction. $A m^{f}$ Cardiol 1983;51:52-60.

21 West JB, Mathieu-Costello O. Stress failure of pulmonary capillaries: role in lung and heart disease. Lancet 1992; 340:762-7.

22 Kay JM, Edwards FR. Ultra-structure of the alveolarcapillary wall in mitral stenosis. F Pathol 1973;111: 239-45.

23 Ohar J, Osterloh J, Ahmed N, Miller L. Diffusing capacity decreases after heart transplantation. Chest 1993;103: decreases

24 Abramson SV, Burke JF, et al. Pulmonary hypertension predicts mortality and morbidity in patients with dilated predicts mortality and morbidity in patients with dilate
cardiomyopathy. Ann Intern Med 1992;116:888-95.

25 Franciosa JA, Baker BJ, Seth L. Pulmonary versus systemic hemodynamics in determining exercise capacity of patients with chronic heart failure. Am Heart $\mathcal{F} 1985$; 110:807-13

26 Packer M, Lee WH, Medina N, Yushak M. Hemodynamic and clinical significance of pulmonary vascular response to long term therapy in patients with severe chronic heart failure. $\mathcal{F}$ Am Coll Cardiol 1985;6:635-45. 